\title{
Lutetium Lu 177 Satoreotide Tetraxetan
}

National Cancer Institute

\section{Source}

National Cancer Institute. Lutetium Lu 177 Satoreotide Tetraxetan. NCI Thesaurus. Code C124929.

A radioconjug ate consisting of the somatostatin antagonistic peptide satoreotide tetraxetan (IR11) that is linked, via the chelating agent dodecanetetraacetic acid (DOTA), to the beta-emitting radioisotope lutetium Lu 177, with potential antineoplastic activity and imaging activity during positron emission tomography/computed tomography (PET/CT). Upon administration, lutetium Lu 177-DOTA-JR11 binds to somatostatin receptors (SSTRs), with high affinity for SSTR2, present on the cell membranes of many types of neuroendocrine tumor (NET) cells. Upon binding and internalization, this radioconjug ate specifically delivers a cytotoxic dose of beta radiation to SSTR-positive cells. SST Rs have been shown to be present in large numbers on NETs and their metastases, while most normal tissues express low levels of SSTRs. 